\title{
Fonograma 108.077: o lundu de George W. Johnson
}

\author{
Carlos Palombini (UFMG, Belo Horizonte, MG) \\ cpalombini@gmail.com
}

\begin{abstract}
Resumo: Um exame do fonograma Gargalhada (pega na chaleira), cançoneta por Eduardo das Neves, expõe a origem da expressão "pegar na chaleira" e revela incongruências nos critérios de catalogação online do Instituto Moreira Salles. Provavelmente datada de 1906, a gravação aparece como um "lundu" em catálogos comerciais de 1915-1926, e as mesmas ideias musicais foram reaproveitadas em outros registros sonoros da Casa Edison comercializados entre 1913 e 1919. A música e o gargalhar que Neves reaproveita foram criados por George Washington Johnson, o primeiro astro negro da gravação mecânica. Mas enquanto o ex-escravo norte-americano se auto-ridiculariza de acordo com estereótipos brancos, o autodenominado "crioulo" encena uma sátira ao comportamento masculino das classes dominantes do Rio. Neste processo, a coon song transforma-se na antitese do gênero.
\end{abstract}

Palavras-chave. Cançoneta; lundu; coon song; fonografia; Casa Edison

\section{Phonogram 108.077 (Brazilian Odeon): George W. Johnson's Iundum}

Abstract: Through an examination of the phonogram Gargalhada (pega na chaleira) [laughter (picking up the kettle)], chansonnette sung by Eduardo das Neves, the origin of the expression "pegar na chaleira" (bootlicking) emerges, together with incongruities in the Instituto Moreira Salles online catalogue. Probably recorded in 1906, six years before the establishment of the Odeon plant in Rio, the piece was labelled as a lundum, a paradigmatically Afro-Brazilian genre, in the 1915-1926 catalogues. The music and laughter that Neves appropriates to himself were created by George W. Johnson, the first black star of early phonography, and reused in other Casa Edison (Brazilian Odeon) recordings on sale from 1913 to 1919. But while the former North American slave ridicules himself in accordance with white stereotypes, the self-designated crioulo stages a satire on the behaviour of upper-class Rio de Janeiro males. In this process, the coon song turns into its antithesis.

Keywords: chansonnette; lundum; coon song; phonography; Brazilian Odeon

\section{1 - Gargalhada}

"Pega na chaleira, cançoneta por Eduardo das Neves para a Casa Edison, Rio de Janeiro": inicia-se assim um fonograma cuja audição me intriga desde o início dos anos sessenta, quando, aos sete anos de idade, recebi a chapa de goma-laca ${ }^{1}$ em cujo selo lê-se, em caracteres prata sobre fundo alaranjado: "International Talking Machine Co m.b.H., Odeon Record, Gargalhada, Eduardo das Neves, No. 108.077, Impresso especialmente para Casa Edison". Segue-se, na voz de Neves, a letra, já enigmática no início dos anos sessenta.
Nesse século de progresso, nessa terra interesseira, Tem feito grande sucesso o tal pega na chaleira. Nesta terra de progresso, nesta terra interesseira, Tem feito grande sucesso o tal pega na chaleira.

Pega o padre ao capitão, ha, ha, ha, ha, ha, ha, ha, ha! ${ }^{2}$ E este ao seu vigário, ha, ha, ha, ha, ha, ha, ha! E o vigário pega ao ha, ha, ha, ha, ha, ha, ha, ha, ha, ha! Ha, ha, ha, ha, ha, ha, ha, ha, ha, ha, ha, ha, ha! Tudo pega na chaleira!

Pobre moço que só fala na missa e no breviário, Quer subir e está pegando na chaleira do vigário. Pobre moço que só fala na missa e no breviário, Quer subir e está pegando na chaleira do vigário. 
Tudo pega na chaleira, ha, ha, ha, ha, ha, ha, ha!

Pega o bispo ao seu vigário, ha, ha, ha, ha, ha, ha, ha, ha, ha, ha, ha, ha, ha, ha!

$\mathrm{Ha}$, ha, ha, ha, ha, ha, ha, ha! Tudo pega! Tudo pega! Ha, ha, ha, ha, ha, ha, ha, ha, ha!

$\mathrm{Ha}$, ha, ha, ha, ha, ha, ha, ha, ha! Tudo pega na chaleira, meu deus! Tudo!

Bispo que anda a correr mundo, que a crisma é seu ideal,

Pega a chaleira no fundo, bem, do seu cardeal.

Bispo que anda a correr mundo, que a crisma é seu ideal,

Pega a chaleira no fundo, bem, do cardeal.

Tudo pega na chaleira, ha, ha, ha, ha, ha, ha, ha, ha!

0 bispo ao capitão, ha, ha, ha, ha, ha, ha, ha, ha, ha, ha, ha, ha, ha, ha, ha!

$\mathrm{Ha}$, ha, ha, ha, ha, ha, ha! Tudo pega na chaleira, ha, ha, ha, ha, ha, ha, ha, ha!

$\mathrm{Ha}$, ha, ha, ha, ha, ha, ha!

Vigário que a lei sagrada soletra contando a tese,

Está pegando na chaleira do bispo da diocese.

Vigário que a lei sagrada sustenta em boa tese,

Está pegando na chaleira do bispo da diocese.

Tudo pega na chaleira, ha, ha, ha, ha, ha, ha, ha!

0 homem mais potente, ha, ha, ha, ha, ha, ha, ha!

Pega também o soldado, ha, ha, ha, ha, ha, ha, ha!

Na chaleira do tenente, ha, ha, ha, ha, ha, ha, ha, ha, ha, ha, ha, ha, ha, ha!

$\mathrm{Ha}$, ha, ha, ha, ha! Ha, ha, ha, ha! Tudo pega na chaleira! Ha, ha, ha,

ha, ha, ha, ha!

De acordo com o Dicionário da língua portuguesa contemporânea da Academia das Ciências de Lisboa (2001), a expressão "pegar na chaleira" - um brasileirismo - significa "bajular, adular, lisonjear". De acordo com o Dicionário brasileiro da língua portuguesa o substantivo masculino e feminino "chaleira" quer dizer "bajulador" na gíria: "O significado provém de os bajuladores do chefe político gaúcho Pinheiro Machado, que conservava no Rio de Janeiro o hábito de tomar chimarrão, estarem sempre atentos para lhe servirem a chaleira de água fervente para 0 preparo da infusão de mate" (SILVA et al. 1975). Ainda segundo o Dicionário brasileiro, "pegar no bico da chaleira" significa "adular, bajular, lisonjear os poderosos". No terceiro volume de $O$ Rio de Janeiro do meu tempo (1938), Luiz Edmundo descreve assim o Senador José Gomes Pinheiro Machado (1851-1915): ${ }^{3}$

Pinheiro Machado, quando aqui chegou, vindo do sul, inspirava pavor. Era um caudilho tisnado pelo sol, forte, cheio de atrevimento e de bravura. Seus feitos, nas campanhas do sul, eram quasi lendarios. Na coxilha, á frente de guerrilheiros destemidos, foi um glorioso centauro. Na refrega, de lança em punho, bombacha panda, e ponche ao vento, era o que mais derrubava, abatia e matava.
Não encontrou pela frente jamais quem lhe tolhesse 0 passo, 0 dominasse ou vencesse. Por isso, onde ia, tinha, fatalmente, que mandar. Sempre. Mandou na campanha, mandou na cidade, acabou mandando no paiz.

Quando começa o seculo, quem manda na politica é elle. E manda como ninguem. É o sr. capitão-mór dos tempos do ouro, em Minas. É o Tutú Marambaia dos altos telhados da politica. Não ha quem ouse contrariar-Ihe as ideas, os desejos e até as caprichosas fantasias. A imprensa inteira vive a lamber-lhe a sola dos sapatos. (COSTA 1938, p.1065)

De acordo com SEVERIANO (2008, p.88), "salvaram-se na primeira década dos novecentos umas poucas revistas como [...] Pega na chaleira (1909), de Raul Pederneiras e Ataliba Reis, que explorava a popularidade da polca 'No bico da chaleira', de Juca Storoni (João José da Costa Júnior)". ${ }^{4}$ Ainda segundo Severiano, esta revista teria difundido a expressão "chaleirar".

No catálogo online do Instituo Moreira Salles (IMS), a Gargalhada aparece em quatro fichas do acervo Humberto Franceschi e duas do acervo José Ramos Tinhorão, correspondendo, possivelmente, a chapas distintas ${ }^{5}$ (vide Ex.1). Todas as fichas dão "Gargalhada (pega na chaleira)" como "título da música". Este título é o mesmo que consta na Discografia brasileira 79 RPM (SANTOS et al. 1982, p.84) e corresponde à amalgamação do título no selo da chapa com o título anunciado no início do fonograma. ${ }^{6}$ Todas as fichas creditam "Neves, Eduardo das" como "intérpretes(s)". Todas registram a "Odeon" como "gravadora". Todas indicam, como "data de gravação" e "data de lançamento", o período 1907-1912, correspondente à estimativa da Discografia brasileira para a totalidade da série 108.000 (SANTOS et al. 1982, p.115). Todavia, no que diz respeito às entradas "gênero musical", "número do álbum", "lado" e "rotações", há discrepâncias, não só entre as fichas dos acervos Franceschi e Tinhorão como também, internamente, entre as quatro fichas do acervo Franceschi. (As duas fichas do acervo Tinhorão são idênticas.)

\section{1 - Gênero musical}

Embora a palavra "lundu" não apareça no selo da chapa e a Gargalhada seja verbalmente apresentada no fonograma como uma cançoneta, é como um lundu que ela figura tanto nos catálogos disponiveis da Casa Edison (FRANCESCHI 2002) ${ }^{7}$ como no primeiro volume da Discografia brasileira 78 RPM (SANTOS et al. 1982, p.84).

\begin{tabular}{|l|l|l|l|l|l|}
\hline & JRT 1 e 2 & HMF 1 & HMF 2 & HMF 3 & HMF 4 \\
\hline gênero musical & lundu & lundu & humor & humor & humor \\
\hline número do álbum & 108077 & 108077 & 108077 & 1080772 & 1080773 \\
\hline lado & indefinido & Lado A & Lado B & único & único \\
\hline rotações & 76 RPM & 78 RPM & 78 RPM & 78 RPM & 78 RPM \\
\hline
\end{tabular}

Ex.1: Discrepâncias entre as fichas do fonograma 108.077 no catálogo online do IMS. 


\section{2 - Número do álbum}

Nos catálogos da Casa Edison (FRANCESCHI 2002) e na Discografia brasileira (SANTOS et al 1982, p.84), bem como no primeiro volume de Panorama da música popular brasileira e em Panorama da música popular brasileira na belle époque, ambos de Ary VASCONCELOS (1964, p.191; 1977, p.284), a Gargalhada aparece como o fonograma 108.077. Não há, na era da gravação mecânica no Brasil, registro de uma série Odeon 1.000.000. Os termos "número do álbum", utilizado pelo IMS, e "número do disco", utilizado na Discografia brasileira 78 RPM, são inadequados. "Álbum" é uma designação curiosa para o que se aproxima mais do que se chamou um dia no Brasil "compacto simples", e que hoje se conhece como single. Por outro lado, "número do disco" é uma expressão inadequada para designar um fonograma num contexto em que um disco é composto de dois fonogramas, um de cada lado da chapa. ${ }^{8}$

\section{3 - Lado}

Os fatos de, nos catálogos disponiveis da Casa Edison, a Gargalhada aparecer sempre antes - ou, mais exatamente, acima - do Balancê, fonograma 108.085, ao qual está invariavelmente acoplada ali, ${ }^{9}$ e o número de referência da chapa assim formada ser sempre o 108.077, indicam que a Gargalhada ocupe, efetivamente, a face comercialmente mais importante. Todavia, nem o exemplar de que disponho nem os catálogos da Casa Edison divulgados por Franceschi fazem distinção entre um "lado A" (ou "1") e um "lado B" (ou "2"). Por sua vez, a designação "lado único" parece dificilmente aplicável, já que todas as chapas da Casa Edison eram duplas, Fred Figner sendo concessionário, desde 12 de dezembro de 1901, da patente do disco de duas faces no Brasil (vide FRANCESCHI 1984, p.58-71; 2002, p.85-94 e 109-113).

\section{4 - Rotações}

$\mathrm{Na}$ cópia de que disponho, o selo da canção Balancê especifica nitidamente "76 voltas por minuto", e seria muito improvável que uma chapa fosse prensada para girar a 76 RPM de um lado e a 78 de outro.

\section{5 - A Catalogação online do IMS}

Conclui-se que as fichas do catálogo do IMS devem ser lidas com cautela, sobretudo no que diz respeito ao acervo Franceschi. ${ }^{10}$ Acrescente-se que os critérios de transferência e processamento digital das gravações estão muito distantes dos praticados por profissionais como Mark Obert-Thorn, Ward Marston ou Andrew Hallifax. ${ }^{11}$

\section{2 - Datação}

De acordo com FRANCESCHI (2002, p.207), a fórmula usada para anunciar a música no fonograma 108.077, concluindo-se com "para a Casa Edison, Rio de Janeiro", sem o endereço, vigorou de 1904 a 1912. A tabela abaixo (Ex.2) mostra as datações estimativas da Discografia brasileira para as séries Odeon imediatamente anteriores, imediatamente posteriores ou parcialmente concomitantes à 108.000 .

0 "Livro de Registro de Gravações da Casa Edison" (reproduzido em FRANCESCHI 2002) fornece "série", 14 "№s", 15 "gênero", "autores" e "artistas", além da data e local das tomadas de todos os fonogramas das séries $120.000 \mathrm{e}$ 137.000 , bem como dos fonogramas 10.327-10.413 da série 10.000 , com as datas estendendo-se de 5 de setembro de 1911 a 15 de abril de 1915, no Rio de Janeiro, em São Paulo e em Porto Alegre. ${ }^{16}$ Não há, no Livro, registro de nenhuma tomada para a série 108.000. Assim, se a Discografia brasileira está correta ao supor que a série 120.000 se inicie com o final da 108.000 (SANTOS et al. 1982, p.115 e 169), as tomadas para a série 108.000 devem ter-se encerrado no final de agosto ou início de setembro de 1911. ${ }^{17}$

No interior da série 108.000 , os fonogramas $108.070-$ 108.085 constituem a primeira sucessão contínua de interpretações de Eduardo das Neves (Ex.3), com quinze itens identificados na Discografia brasileira (SANTOS et al. 1984, p.84-85). A série 108.000 estendendo-se de janeiro de 1907 a agosto de 1911 e constando de 844 fonogramas, obtém-se uma média de quinze fonogramas por mês. Esta aproximação situaria os fonogramas de número

\begin{tabular}{|l|l|l|}
\hline série Odeon & data estimada & diâmetro \\
\hline $40.000-40.777$ & $1904-1907$ & $27 \mathrm{~cm}$ \\
\hline $108.000-108.843$ & $1907-1912$ & $27 \mathrm{~cm}$ \\
\hline $10.000-10.412^{12}$ & $1907-1913$ & $19 \mathrm{~cm}$ \\
\hline $70.000-70.084$ & $1908-1912$ & $35 \mathrm{~cm}^{13}$ \\
\hline $70.500-70.515$ & $1908-1912$ & $30 \mathrm{~cm}$ \\
\hline $137.000-137.107$ & $1912-1914$ & $25 \mathrm{~cm}$ \\
\hline $120.000-120.999$ & $1912-1915$ & $27 \mathrm{~cm}$ \\
\hline
\end{tabular}

Ex.2: Datações estimativas de SANTOS et al. (1982) para séries imediatamente anteriores, imediatamente posteriores ou parcialmente concomitantes à Odeon 108.000 . 


\begin{tabular}{|l|l|l|l|l|}
\hline fonograma & título 18 & gênero & matriz & Com \\
\hline 108.070 & O Soldado que perdeu a parada & lundu & XR-603 & violão de E. das N. \\
\hline 108.071 & E Eu nada & lundu & & violão de E. das N. \\
\hline 108.072 & Bolim-bolacho & lundu & & violão de E. das N. \\
\hline 108.073 & Marocas & lundu 19 & & violão de E. das N. \\
\hline 108.074 & laiazinha & lundu & & violão de E. das N. \\
\hline 108.075 & Pai João & lundu 20 & XR-608 & violão de E. das N. \\
\hline 108.076 & Isto é bom & lundu & XR-607 & violão de E. das N. \\
\hline 108.077 & Gargalhada (pega na chaleira) & lundu & XR-610 & Violão \\
\hline 108.078 & OAmolador & lundu & XR-611 & violão de E. das N. \\
\hline 108.079 & OAquidaban & canção & XR-612 & Violão \\
\hline 108.080 & República de estudantes 21 & cômico & XR-613 & viol., M. Pinheiro, Nozinho \\
\hline 108.081 & Rolo em um bonde 22 & cômico & XR-614 & viol., M. Pinheiro, outros \\
\hline 108.082 & Seu Gouveia & canção & XR-615 & violão, outros \\
\hline 108.083 & & & & \\
\hline 108.084 & Estranguladores do Rio & canção & & violão de E. das N. \\
\hline 108.085 & Balancê & canção & XR-618 & viol. de E. das N. [e coro] 23 \\
\hline
\end{tabular}

Ex.3: Primeira sucessão ininterrupta de fonogramas de Eduardo das Neves na série 108.000.

108.070 a 108.074 nos últimos dez dias de maio de 1907 e os de número 108.075 a 108.085 nos vinte primeiros dias de junho do mesmo ano.

Em Panorama da música popular brasileira, VASCONCELOS (1964, p.191) data de "entre 1904 e 1912": O Soldado que perdeu a parada, Bolim-bolacho, Isto é bom, GargaIhada, Rolo em um bonde e Balancê. Na página 284 de Panorama da música brasileira na belle époque, o mesmo VASCONCELOS (1977, p.284) data de "entre 1906 e 1912": O Soldado que perdeu a parada, Bolim-bolacho, Pai João, Isto é bom, Gargalhada, O Aquidabã, Rolo em um bonde, Estranguladores do Rio e Balancê. Na mesma obra, 48 páginas adiante, ele data de "entre 1906 e 1909" o Rolo em um bonde (VASCONCELOS 1977, p.332). Finalmente, o Dicionário Cravo Albin da música popular brasileira (ALBIN 2006, p.1032) data de 19070 Soldado que perdeu a parada, E Eu nada, Bolim-bolacho, Marocas, laiazinha, Pai João, 0 Amolador, 0 Aquidaban [sic], Rolo em um bonde, Seu Gouveia, Estranguladores do Rio e Balancê. Ressaltando o caráter estimativo das datações, FRANCESCHI (2008) não hesita em dizer que a Gargalhada seja de 1906. Há boas razões para isto.

Como Eduardo das Neves canta em 0 Aquidabõ, "Foi essa noite fatal de 21 de janeiro [de 1906] que trouxe pesado luto ao pavilhão brasileiro: o valente Aquidabõ, colosso de mil guerreiros, desfez-se no mar sagrado com seus bravos marinheiros". ${ }^{24}$ Já o caso narrado em Estranguladores do Rio, o assassinato, por Eugênio Rocca e Justino Carlo (o Carletto), de Carlo Fuoco, de dezessete anos de idade, e Paulino Fuoco, de quinze, sobrinhos do joalheiro italiano Jacob Fuoco, de cuja loja, no número 11 da Rua da Carioca, eram funcionários, ocorreu na noite de 14 para 15 de outubro de $1906 .{ }^{25}$

Vagalume (João Guimarães) afirma em 1933 que "o povo se acostumou a ouvir Eduardo das Neves cantar ao violão os acontecimentos de maior divulgação, ocorridos no cenário político de nossa Pátria" (GUIMARÃES 1978, p.70). Como diz o cantor acerca de suas obras na "Declaração" que abre o Trovador da malandragem, "o muito merecimento que têm (e é por isso que tanto sucesso causam) é que eu as faço segundo a oportunidade, à proporção que os fatos vão ocorrendo, enquanto a cousa é nova e está no domínio público. É o que se chama 'bater o malho enquanto o ferro está quente'" (NEVES 1905, p.4). Ora, Eduardo das Neves glosava o "assunto do dia" (VASCONCELOS 1964, p.45), ${ }^{26}$ e, em junho de 1907, entre 0 assunto do dia e o dia do assunto, se teriam passado mais de um ano e quatro meses, no caso do naufrágio, ou cerca de oito meses, no caso do latrocínio. ${ }^{27}$

Fred Figner deu início à comercialização de cilindros em 1897 (FRANCESCHI 1984, p.22; 2002, p.31), ${ }^{28}$ isto é, três anos antes da data de registro da Casa Edison na Junta Comercial (FRANCESCHI 1984, p.31-32; 2002, p.50-51). 0 Catalogo de 1902 da Casa Edison mostra que A gargaIhada (com artigo) já estava à venda em 1902 como o cilindro A-492, na voz de Eduardo das Neves, sem menção de gênero. Todavia, se, nos Estados Unidos, "das primeiras gravações feitas em folha de estanho em 1877 às últimas produzidas em celulóide em 1929, os cilindros atravessaram meio século de desenvolvimentos tecnológicos da 
gravação de som" (SEUBERT s.d.), no Brasil, nem os catálogos gerais de 1915, 1918, 1919, 1920, 1924 e 1926, nem os suplementos de 1913 e 1914 - isto é, a totalidade dos catálogos divulgados por FRANCESCHI (2002) - fazem qualquer alusão a fonógrafos ou cilindros. FRANCESCHI (1984, p.32) identifica no Diário Oficial de 11 de setembro de 1907, o registro, por Fred Figner, da marca de cilindros Phrynis e conclui que "discos e cilindros conviveram harmoniosamente durante as duas primeiras décadas deste século" (FRANCESCHI 1984, p.32). Em $A$ Casa Edison e seu tempo, ele é um pouco mais preciso: "o cilindro permaneceu presente, com produção significativa, por toda a primeira década do século XX e boa parte da segunda" (FRANCESCHI 2002, p.43). Já a chapa 108.077 aparece em catálogo, sempre como um lundu: em 1915, sob a rubrica "modinhas, canções, cançonetas, monólogos e lundus" (p.59); em 1918, sob a rubrica "modinhas, canções e lundus" (p.32); em 1919, sob a rubrica "modinhas, canções e lundus" (p.31); em 1920, sob a rubrica "modinhas, canções e lundus" (p.26); em 1924, sob a rubrica "série 108.000" (p.31); e em 1926, sob a rubrica "por Eduardo das Neves" (p.6).

Em meu exemplar, o selo do Balancê é o de miolo azul e borda roxa, com os caracteres em dourado e a bandeira esvoaçante do Brasil no hemisfério superior. Se Franceschi tem razão em dizer que este selo foi aplicado em "reprensagens comemorativas da inauguração da fábrica Odeon do Rio de Janeiro" em dezembro de $1912{ }^{29}$ e que "somente gravações anteriores a 1912 [...] foram reprensadas e receberam etiqueta especial [...] num curto período de 1913" 30 (FRANCESCHI 2002, p.204), é razoável admitir que a Gargalhada tenha estado à venda no ano de 1913, não aparecendo nos catálogos disponíveis deste ano e do seguinte, justamente os mais próximos à data provável de gravação, porque, para os anos de 1913 e 1914, não dispomos dos catálogos gerais, mas apenas de suplementos. 0 sucesso posterior da chapa sugere que 0 cilindro A Gargalhada, independentemente de seu conteúdo, possa ter estado à venda por quatro anos desde seu anúncio no Catalogo de 1902. Não é improvável que, a partir da data de gravação do fonograma 108.077, cilindro e chapa tenham figurado nos catálogos perdidos, até que a segunda desbancasse a primeira, um fato consumado no catálogo Discos Odeon 1915 Casa Murano. A
Gargalhada deve, portanto, ter sido comercializada por cerca de um quarto de século, ininterruptamente.

Mas isto não é tudo: ela foi reaproveitada também, gargalhar e música, fragmentariamente ( $\mathrm{e}$, ao que tudo indica, com menos sucesso), sob outros títulos (vide Ex.4). 0 Supplemento A do catálogo de 1913 (p.5) apresenta 0 fonograma 40.493, "Febre amarela", uma cançoneta, ${ }^{31}$ na voz de Geraldo Magalhães, com música idêntica à do fonograma 108.077 e gargalhar semelhante, mas letra diferente. 0 mesmo Suplemento $A "$ de 1913 (p.8) e o Catalogo geral de 1918 (p.60) apresentam o fonograma 40.631, $A$ Risada, peça "cômica" (no suplemento de 1913) ou "cançoneta" (no catálogo de 1918), na voz de Edmundo André, com gargalhar análogo ao do fonograma 108.077, mas letra e música diferentes. 0 catálogo Discos Odeon 1915 Casa Murano (p.56) e os Catalogos gerais de 1918 (p.23) e 1919 (p.23) apresentam o fonograma 40.169, A Vacina obrigatória, uma cançoneta, na voz de Mário Pinheiro, com música idêntica à do fonograma 108.077, mas sem o gargalhar, e com letra diferente. 0 Suplemento $A$ do catálogo de 1913 (p.15) e o Catalogo geral de 1918 (p.65) apresentam o fonograma 108.760, As Eleições de Piancó, uma "gargalhada" (aqui promovida ao estatuto de gênero musical) ${ }^{32}$ na voz de Eduardo das Neves, com melodia e letra diferentes das do fonograma 108.077, mas com gargalhar análogo.

Provavelmente baseada no próprio autor (NEVES 1926, p.4), a literatura (VASCONCELOS 1964. p.5; 1977, p.282; SILVA e OLIVEIRA 1979, p.15; ABREU 2003, p.76; ALBIN 2006, p.1032; FERLIM 2006, p.75) tende a dar a GargaIhada hispano-americana como uma modinha ou cançoneta de Eduardo das Neves. Ferlim (2006, p.75) chega a perguntar-se se ela corresponderia ao cilindro A-492. Como, de acordo com Franceschi, nenhum dos cilindros brasileiros é audivel hoje, por questões técnicas, ${ }^{33}$ parece impossivel responder a esta pergunta. FRANCESCHI (2008) me fez ouvir a Gargalhada hispano-americana ao telefone. Trata-se, exatamente, da mesma música e do mesmo gargalhar do fonograma 108.077, com letra distinta. De acordo com FRANCESCHI (2008), o disco Zon0-Phone no qual Gargalhada hispano-americana foi gravada está depositado no Instituto Moreira Salles. Todavia, nem o Catalogo de 1902, nem a Discografia brasileira 78

\begin{tabular}{l|l|l|l|l|l|l|l|l} 
& 1913 & 1914 & 1915 & 1918 & 1919 & 1920 & 1924 & 1926 \\
\hline Gargalhada & & & & & & & & \\
\hline Febre amarela (música =, gargalhada $\approx$ ) & & & & & & & & \\
\hline A Risada (gargalhada $\approx$ ) & & & & & & & & \\
\hline A Vacina obrigatória (música =) & & & & & & & & \\
\hline As Eleições de Piancó (gargalhada $\approx$ ) & & & & & & & &
\end{tabular}

Ex.4: Incidência, em catálogos da Casa Edson, de fonogramas com música ou gargalhar iguais ou semelhantes aos do fonograma 108.077 . 
RPM (SANTOS et al. 1982, p.1-32), nem os websites do Instituto Moreira Salles, da Fundação Joaquim Nabuco ou do Projeto Disco de Cera (Aquivo Nirez) trazem qualquer registro desta gravação. Finalmente, o "grandioso e extraordinario repertório de modinhas brasileiras" (sic) de 1905, Mysterios do violão, de Eduardo das Neves, contém o poema Questão do Acre, designado como "nova gargaIhada", ${ }^{34}$ e que deve ter sido cantado ao som da música do Pega na chaleira.

\section{3 - Autoria}

No prefácio de seu Trovador da malandragem, por volta de 1903, Eduardo das Neves pergunta: "Por que motivo duvidaes, isto é, não acreditais, quando apparece qualquer 'chôro', qualquer composição minha, que agrada, que cahe no gôsto do publico, e é decorada, repetida, cantada por toda a gente, e em toda a parte - desde nobres salões, até pelas esquinas, em horas mortas da noite?!" (NEVES 1926, p.3). ${ }^{35}$ João do Rio conclui, em 1908, que, ao contrário do Bahiano, "Dudú [...] canta apenas as suas obras" (BARRETO 1910, p.306). E Vagalume reitera, em 1933:

Nunca se impôs como, realmente, deveria ter feito.

Em compensação - aqui que ninguém nos ouça, nunca se enfeitou com penas de pavão... nem nunca se locupletou com os resultados dos trabalhos dos outros...

Certa vez escrevi, a seu pedido, uma cançoneta: PEGA NA CHALEIRA - que ele musicou, enquanto o diabo esfregou um olho, para cantar duas horas depois, na noite de seu benefício, em Santa Cruz.

Pois bem, quando teve que gravar a chapa na Casa Edison, veio pedir autorização e eu não consenti em figurar o meu nome como autor da letra.

Revi, concertei ajeitei uma infinidade de peças da autoria de Eduardo.

Ele era interessante escrevendo peças - não fazia a separação das cenas - era tudo corrido!

Quando anunciava uma peça, como de sua autoria, é porque o era mesmo.

Nunca botou o seu nome aos trabalhos dos outros...

Há por aí quem não assine com correção o próprio nome, e se inculque autor de várias obras teatrais... e já houve mesmo tempo em que nada subia à cena em determinada casa de espetáculos sem o nome do consagrado escritor!...

Eduardo, porém, era vinho de outra pipa, como vulgarmente se diz, e submetia tudo quanto o seu bestunto gerava à apreciação de pessoas que lhe pudessem corrigir os erros. Jamais o grande artista fez cortesia com o chapéu alheio - porque, o que apresentava como seu, era seu de verdade. (GUIMARÃES 1978, p.68)

Jota Efegê observou, em 1965, que "houve um punhado de canções (lundus, modinhas, chulas, etc.) que o teve como criador ou principal intérprete. Muitas delas, por isto, ficaram consignadas na biografia do bardo do povo como sendo de sua própria e exclusiva autoria, quando, apenas, houve feitura de versos conduzidos por músicas alheias" (GOMES 1978, p.159).

\section{4 - Gargalhadas "inglezas"}

Encimado pelo cabeçalho "gargalhadas inglezas", encontramos no Catalogo de 1902 da Casa Edison de Fred Figner, "importador de phonographos, gramophones e novidades americanas", o anúncio de dois cilindros, o 379, "Laughing Song", e o 380, "Laughing Coon" (vide Ex.5). Entre o cabeçalho e os fonogramas, a figura de um cidadão de meia-idade convida-nos, sorridente, a conhecermos estas instâncias de humor "britânico" (o qual, como é sabido, nunca teve no gargalhar um meio privilegiado de expressão). Seria necessário um tipo de atenção que não costumamos dispensar a catálogos publicitários para nos darmos conta de que, apesar da alvura da sua tez, 0 nariz do cidadão é grande e chato. Trata-se de George Washington Johnson, o primeiro astro negro da fonografia, nascido escravo numa fazenda da Virgínia em $1846 .{ }^{36}$

De acordo com um anúncio publicado na revista Phonogram em novembro de 1900 (p.14-15, apud BR00KS 2004, p.24), Johnson começou a gravar para Thomas Alva Edison em 1877. Levando em conta que o primeiro fonógrafo foi construído por Edison em dezembro de 1877 e apresentado na Casa Branca em abril de 1878, BR00KS (2004, p.24) conjetura que estas gravações, se realmente ocorreram, ${ }^{37}$ devem ter-se realizado em 1878 ou 1879. Seja como for, em junho de 1890, meses depois do início das gravações comerciais, a New York Phonograph Company já tinha em catálogo a Laughing Song e o Whistling Coon, as duas especialidades de Johnson. Nesta época, Johnson gravava também para a New Jersey Phonograph Company (BRO0KS 2004, p.30), de Edison. Em 1891 e 1892 ele regravou seus números para a North American Phonograph Company, com distribuição nacional. Em 1892 a Columbia adicionou a seu catálogo a Laughing Song e o Whistling Coon na voz de John Y. AtLee. A New Jersey contra-atacou revelando que Johnson era negro e que, portanto, a versão registrada para este selo era a legítima. Em março de 1894 a United States Phonograph Company, divulgou que "até o momento, mais de 2.500 gravações destas duas canções foram realizadas por este artista, e os pedidos parecem aumentar, ao invés de diminuir" (BROOKS 2004, p.30). No mesmo ano, Johnson registrou direitos sobre a música e a letra da Laughing Song e começou a gravá-la como parte dos sketches fonográficos do Spencer, William and Quinn Minstrels. ${ }^{38}$ Em 1897 estes sketches passaram a ser lançados pela Columbia, que também comercializou os fonogramas solo do artista. Em 1894, Emile Berliner havia dado início à 
venda de discos em ampla escala e Johnson foi convidado para registrar seus dois sucessos em disco em 1895, 1896, 1897 e 1898. Na segunda metade dos anos 1890, ele os gravou também para vários selos menores. Os catálogos da Columbia para o período 1895-1897 afirmavam que nenhum outro item vendia tanto quanto as duas canções de Johnson. Walcutt and Leeds, fabricantes dos New York Cylinders, chamaram-nas, em 1896, de "duas grandes especialidades que têm sido vendidas no mundo inteiro". Um catálogo não identificado do período fala de 38.000 cilindros. Publicada em 1894, a partitura da Laughing Song (vide Ex.6 e 7) fala de 50.000 gravações, só em cilindro. Neste ano, o Edison Phonograph News afirmou que "a Laughing Song de George Washington Johnson tem vendido mais do que qualquer outro registro fonográfico". Os dois títulos de Johnson foram imitados, traduzidos e "pirateados". Whistling Coon teve versões em francês e em sueco. No final dos anos 1890, quando várias companhias de gravação tentavam estabelecer escritórios no exterior, vendendo registros locais e sucessos importados, Laughing Song e Whistling Coon foram incluídos num dos primeiro catálogos ingleses de Berliner, datado de 16 de novembro de 1898, reaparecendo em 22 de fevereiro de 1899. Uma gravação desta época, provavelmente para a New Jersey Phonograph Company (vide referências fonográficas), inicia-se com o anúncio do apresentador: "The Laughing Song, by Mr George W. Johnson!"

As I was coming 'round the corner I heard some people say: Here comes a dandy darky, here he comes this way. His heel is like a snow plow, his mouth is like a trap, And when he opens it gently you will see a fearful gap.

And then I laugh, ha, ha, ha, ha, ha, ha, ha, ha, ha, ha, ha! ${ }^{39}$ I couldn't stop my laughing, ha, ha, ha, ha, ha, ha, ha, ha, ha, ha, ha! Ha, ha, ha, ha, ha, ha, ha, ha, ha, ha, ha!

I couldn't stop my laughing, ha, ha, ha, ha, ha, ha, ha!

They said his mother was a princess, his father was a prince, And he'd been the apple of their eye if he had not been a quince, But he'll be the king of Africa in the sweet by and by. And when I heard them say it why I laughed until I cried.

And then I laugh...

So now kind friends just listen to what I'm going to say: I've tried my best to please you with my simple little lay. Now whether you think it's funny or a quiet bit of chaff, Why all I'm going to do is just to give this little laugh.

And then I laugh...

A letra de Johnson poderia traduzir-se assim:

Eu estava dobrando a esquina quando ouvi gente dizer: Vem aí o peralvilho preto, ${ }^{40}$ ai vem ele.

Seu calcanhar é como um limpa-neves, sua boca um alçapão,

E quando ele a abre suavemente você vê um buraco medonho.

E eu dou risada, ha, ha, ha, ha, ha, ha, ha, ha, ha, ha, ha! Não pude conter o riso, ha, ha, ha, ha, ha, ha, ha, ha, ha, ha, ha! $\mathrm{Ha}$, ha, ha, ha, ha, ha, ha, ha, ha, ha, ha!

Não pude conter o riso, ha, ha, ha, ha, ha, ha, ha!

Disseram que sua mãe era uma princesa, seu pai um principe, E ele teria sido a menina de seus olhos se não tivesse sido um sonso, ${ }^{41}$ Mas ele será o rei da África se deus quiser. ${ }^{42}$
E quando eu ouvi isto eu ri até chorar.

E eu dou risada...

Agora, caros amigos, ouçam o que vou dizer:

Fiz o que pude para agradá-los com meus versinhos singelos. Agora, se acharam engraçada ou meio fraca a brincadeira,

Tudo o que farei é dar esta risadinha.

E eu dou risada...

\section{5 - Risada de negro}

A apropriação e re-significação por artistas brasileiros de músicas "norte-americanas aficanas" é um fato tão antigo quanto a própria indústria fonográfica. Ela resulta da clivagem espaço-temporal intrínseca à reprodutibilidade técnica do som: aquilo que soou em determinado tempo e em determinado lugar ressoa em outro tempo e em outro lugar, sendo escutado, necessariamente, com outros ouvidos. Desta forma, o evento original é descontextualizado. Assim, a Laughing Song, uma coon song ${ }^{43}$ cantada por um ex-escravo norte-americano, transforma-se na Gargalhada no Brasil: uma cançoneta na qual um afro-descendente apresenta o puxa-saquismo como traço dominante das classes favorecidas. Neste processo, o gênero adquire um novo significado. De modo oposto, nas primeiras décadas do século $X X_{\text {, }}$ At a Georgia Camp Meeting, o celebérrimo cakewalk ${ }^{44}$ do compositor branco norte-americano Kerry Mills (vide Ex.8), dá origem a vários fonogramas no Brasil: ${ }^{45} \mathrm{com}$ a Banda do Corpo de Bombeiros (Odeon 40.115), com a Banda da Casa Edison (Odeon 10.015 e 40.057), com o pianista Artur Camilo (Odeon 40.210), com o cantor J. G. Leonardo e banda (Victor Record 98.720). ${ }^{46} \mathrm{Em} \mathrm{O}$ Mulato de arrelia, J. G. Leonardo, um cantor de etnia indeterminada, personifica a bravata de um negro de subúrbio em visita à capital federal. 0corre aqui o reverso do processo anteriormente descrito: no cakewalk nacionalizado parodia-se o comportamento de um negro suburbano em visita à capital federal.

Seja como for, através da associação entre o empresário europeu Fred Figner e "o crioulo Dudu das Neves", o trabalho do ex-escravo norte-americano Johnson, explorado pela nascente indústria fonográfica norteamericana, passa a ser explorado também no Brasil por aproximadamente um quarto de século. Este fenômeno tem lugar no momento em que, nos Estado Unidos, o surgimento do processo de matrizes fonográficas transformava Johnson num artista dispensável e, aos sessenta anos de idade, sem trabalho.

No dia 6 de maio de 1905, o influente crítico negro Sylvester Russell ${ }^{47}$ escreveu nas páginas do Indianapolis Freeman: ${ }^{48}$

Homens que escrevem letras para canções não podem mais escrever degenerações vergonhosas como a letra de Whistling Coon e esperar que editores respeitáveis aceitem-nas, ainda que a música seja boa. Os compositores não devem musicar palavras que constituam um insulto direto ou uma insinuação indireta à raça parda. Este estilo de literatura não é mais apreciado. (Apud BROOKS 2004, p.66) 


\section{E Brooks continua:}

Os últimos dias de George Johnson foram verdadeiramente sombrios. Sua renda há muito se reduzira a quase nada e, gradualmente, seu nome foi-se perdendo de vista. Seu último cilindro na Columbia saíra de catálogo em 1908. Em 1910 a Victor eliminou o último dos discos que ele gravara e Edison fez o mesmo em 1912. Em 1913 um único disco de sua Negro Laughing Song estava disponivel ainda, feito pela Columbia anos antes, mas seu nome sequer constava no selo. Ao invés de creditar o artista, continha simplesmente as palavras "an old standard". 0 número minstrel de Len Spencer no qual aparecia a Laughing Song continuava em catálogo, mas também não mostrava o nome de Johnson. (BROOKS 2004, p.67)

Johnson faleceu em Nova York no dia 26 de janeiro de 1914 , aos sessenta e sete anos de idade. Em 1918, a música de sua Laughing Song e a gargalhada que ele inventou eram vendidas no Brasil sob os números de fonograma 108.077, 108.760, 40.169 e 40.631 (vide Ex.4), todos em oferta no Catalogo geral da Casa Edison do Rio de Janeiro, Odeon brasileira.

\section{6 - Observações finais: de onde vem o lundu?} A historiografia consagrou as trajetórias inversas da modinha e do lundu ${ }^{49}$ - da casa grande à senzala, e viceversa - como emblema da miscigenação musical brasileira. No momento em que desigualdades econômicas emergem com a nitidez dos números, demonstrando a opressão econômica e cultural da componente menos clara da mistura, é lícito perguntar em que medida esta construção histórica não constitui, ela própria, um instrumento de dominação. 0 presente trabalho mostra que o lundu-canção pode se originar menos das senzalas cafeeiras ou açucareiras do que das vantagens econômicas que a vida urbana de uma grande metrópole do norte dos Estados Unidos ofereceu a um ex-escravo. E em que medida a anatematização sistemática dos elos - problemáticos, ${ }^{50}$ mas evidentes - entre a música brasileira e a norte-americana não constitui, mais que uma expressão de nacionalismo xenófobo, uma rejeição à arte negra norte-americana, vale dizer, um ato de fobia racista?

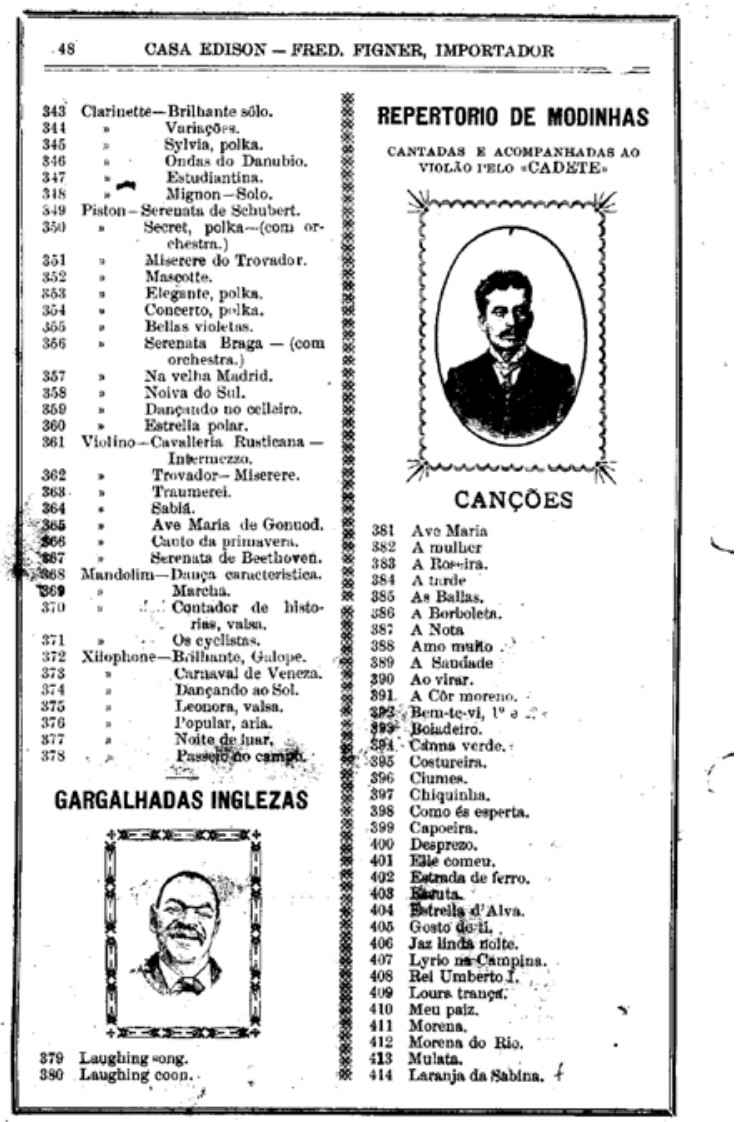

Ex.5: Página do Catalogo de 1902 da Casa Edison, mostrando a imagem anônima de George W. Johnson (embaixo, à esquerda), provavelmente extraída da foto que ilustra a publicação da Laughing Song em 1894 (vide Ex.6).

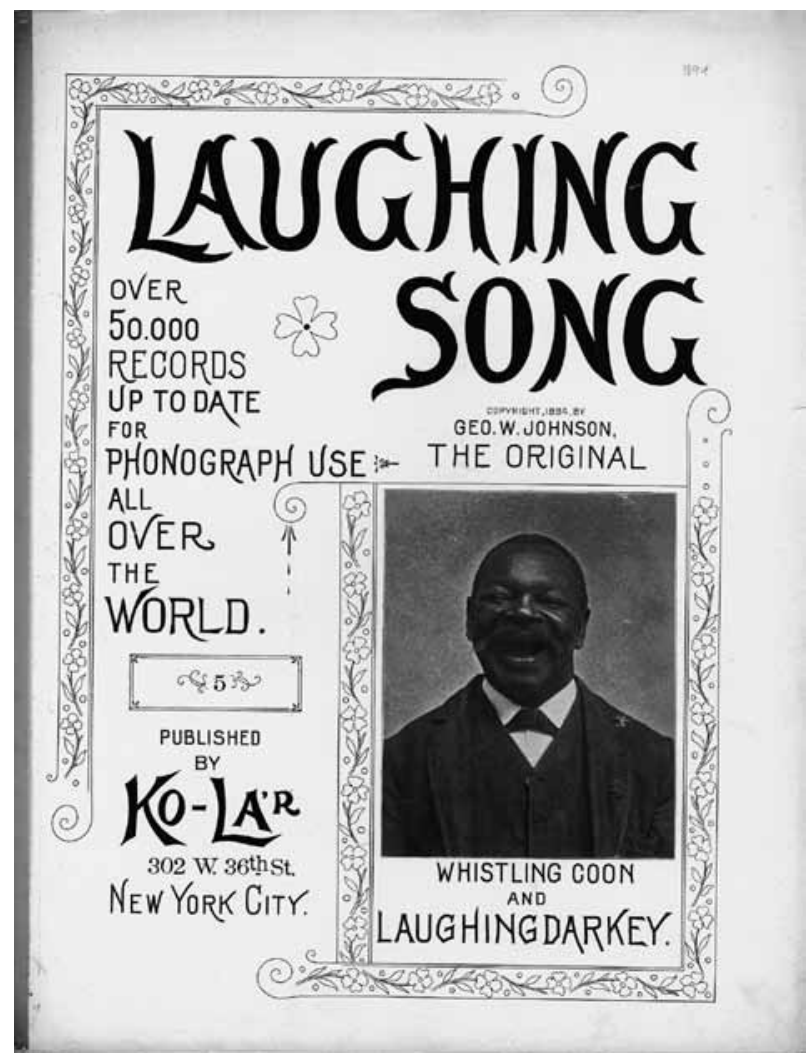

Ex.6: Capa da edição de 1894 da Laughing Song, com a foto de George Washington Johnson, detentor dos direitos sobre a letra e a música. 


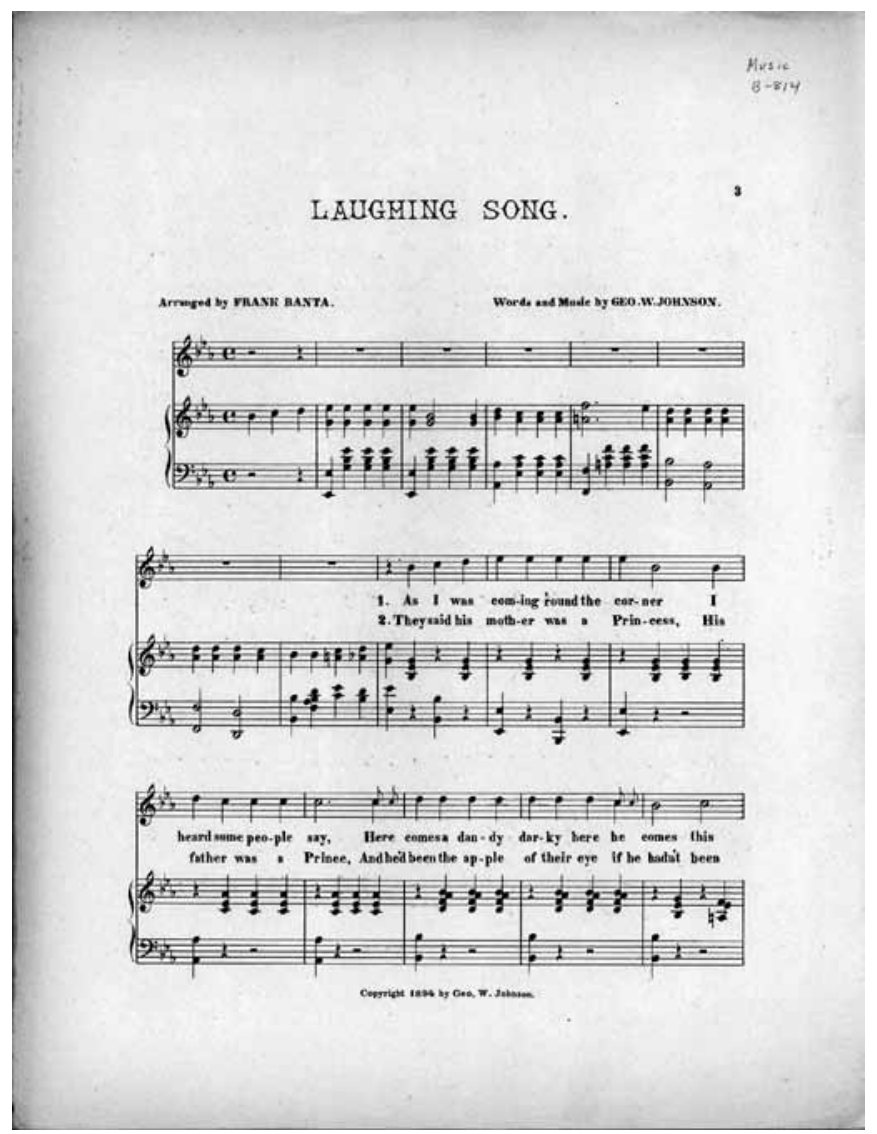

Ex.7: Primeira página da Laughing Son, de George W. Johnson, na edição de 1894.

This March was not intended to be a part of the Religious Exercises "At a Georgia Campmeeting - but when the young folks got together they felt in a quiet place near by

\section{AT A GEOR GIA CAMPMEETING} MARCH.
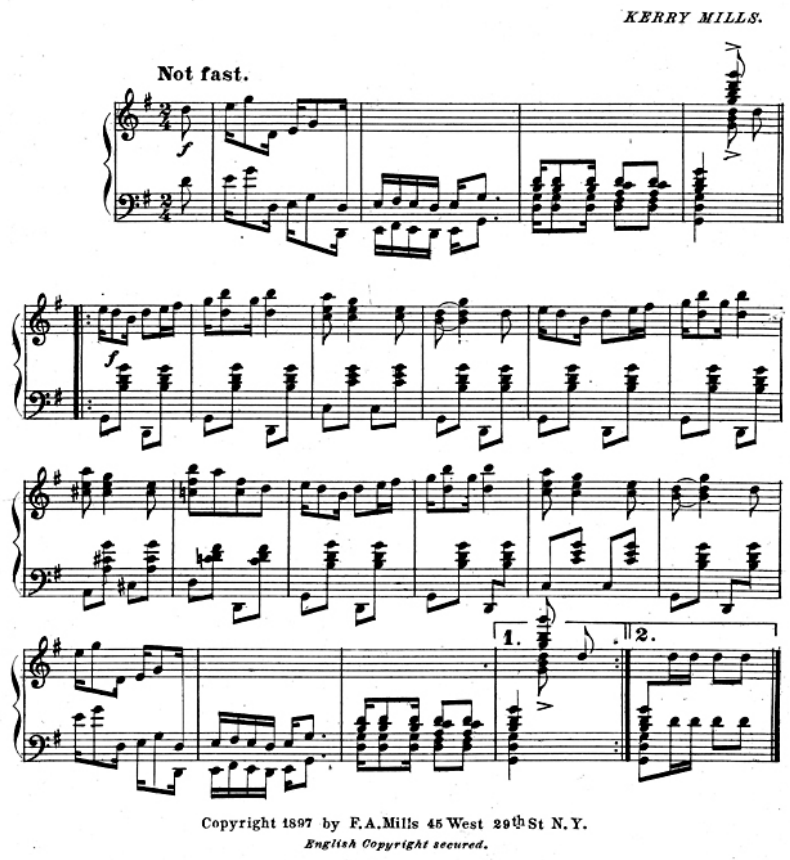

Ex.8: At a Georgia Camp Meeting (1897) de Kerry Mills (1869-1948), "o maior de todos os cakewalks" (WONDRICH, 2003, p.65) 


\section{Referências}

ABBOT, Lynn e Doug SEROFF. 2002. Out of Sight: The Rise of African American Popular Music. Jackson: University Press of Mississippi.

ABREU, Martha. 2003. "Eduardo das Neves (1874-1919): histórias de um crioulo malandro". In Denise Pini Rosalem da Fonseca (org.). Resistência e inclusão: história, cultura, educação e cidadania afro-descendentes. Rio de Janeiro: PUCRio e Consulado Geral dos Estados Unidos, v. 1, p.73-87.

ALBIN, Ricardo Cravo. 2006. "Eduardo das Neves". Dicionário Cravo Albin da música popular brasileira. Rio de Janeiro: Paracatu, p.526 e 1032-1033. Online: <www.dicionariompb.com.br>. Acessado em 25 de maio de 2008.

ALENCAR, Edigar. 1979. 0 carnaval carioca através da música. Rio de Janeiro: Francisco Alves, INL e MEC, $3^{a}$ ed. corrigida, ampliada e atualizada.

BARBOSA, Orestes. 1923. Ban-ban-ban!. Rio de Janeiro: Benjamim Costallat e Miccolis.

BARRETO, João Paulo Emílio Cristóvão dos Santos (João do Rio). [1908]. A alma encantadora das ruas. Rio de Janeiro e Paris: Garnier, 1910. Online: <www.dominiopublico.gov.br/pesquisa/DetalheObraForm.do?select_action=Ctco_ obra $=2051>$. Acesso em 4 de outubro de 2009.

BÉHAGUE, Gerard. 2002. "Bridging South America and the United States in Black Music Research". Black Music Research Journal 22 (1): 1-11.

BROOKS, Tim. 2004. Lost Sounds: Blacks and the Birth of the Recording Industry, 1890-1919. Urbana e Chicago: University of Illinois Press.

BURNIM, Mellonee V. e Portia K. MAULTSBY. 2006. "Glossary". In BURNIM e MAULTSBY orgs 2006, p.643-649.

BURNIM, Mellonee V. e Portia K. MAULTSBY (orgs). 2006. African American Music: An Introduction. New York e London: Routledge.

COSTA, Luiz Edmundo de Melo Pereira da (Luiz Edmundo). 1938. O Rio de Janeiro do meu tempo: ilustrações originaes de Marques Junior, Henrique Cavalleiro, Armando Pacheco, Raul, Calixto, Gil, J. Carlos, Rocha Daniel, Julião Machado, Lobão e outros. Photographias de Marc Ferrez, Luiz Bueno, W. Crown e Augusto Malta. Rio de Janeiro: Imprensa Nacional, $3 \mathrm{vv}$.

FERLIM, Uliana Dias Campos. 2006. "A polifonia das modinhas: diversidade e tensões musicais no Rio de Janeiro na passagem do século XIX ao XX". Campinas: Unicamp, dissertação de mestrado em História. Online: <libdigi.unicamp.br/ document/?code=vtls000376567>. Acesso em 4 de outubro de 2009.

FRANCESCHI, Humberto Moraes. 2008. Entrevista telefônica concedida ao autor, 23 e 24 de maio e 14 de julho.

---. 2002. A Casa Edison e seu tempo. Rio de Janeiro: Sarapuí (com 4 CDs de áudio e 5 de imagem).

---. 1984. Registro sonoro por meios mecânicos no Brasil. Rio de Janeiro: Studio HMF.

GOMES, João Ferreira (Jota Efegê). 1966. "Dudu, o bombeiro boêmio". 0 Jornal, 10 de julho. Citado de Figuras e coisas da música popular brasileira. Rio de Janeiro: MEC-Funarte, 1978, v. 1, p.177-179.

---. 1965. "Eduardo da Neves, da cançoneta, da seresta e também do carnaval". 0 Jornal, 28 de novembro. Citado de Figuras e coisas da música popular brasileira. Rio de Janeiro: MEC-Funarte, 1978, v. 1, p.158-160.

GUIMARÃES, Francisco (Vagalume). [1933]. "O Diamante Negro". Na roda do samba. Rio de Janeiro: Typ. São Benedicto. Citado da seg. ed. Rio de Janeiro: Funarte, 1978, p.65-75.

HALLIFAX, Andrew. 2008. "Making Transfers from 78 RPM Sources: the CHARM Transfer Engineer's Approach". Online: $<$ www.charm.rhul.ac.uk/content/KCL_resources/making_transfers_AH.html . Acesso em 29 de maio de 2008.

HARER, Ingeborg. 2006. "Ragtime". In BURNIM e MAULTSBY orgs 2006, p.127-144.

Instituto de Lexicologia e Lexicografia da Academia das Ciências de Lisboa. 2001. Dicionário da língua portuguesa contemporânea da Academia das Ciências de Lisboa. Lisboa: Verbo, 2 vv.

LISBOA Júnior, Luiz Américo. 1996. "Eduardo da Neves, nosso primeiro cronista musical". Jornal Agora (Itabuna), 21-27 de abril. Citado de Oitenta e um temas da música popular brasileira. Itabuna: Agora, 2000, p.182-189.

NEVES, Eduardo das. 1905. Mysterios do violão: grandioso e extraordinario repertorio de modinhas brasileiras. Rio de Janeiro: Quaresma.

---. [c. 1903]. 0 trovador da malandragem. Rio de Janeiro: Quaresma, 1926 (ii).

PARTRIDGE, Eric, editado por Paul BEALE. 1989. A Concise Dictionary of Slang and Unconventional English Edited by Paul Beale from 'A Dictionary of Slang and Unconventional English' by Eric Partridge. London: Routledge.

PINHEIRO, Abílio Soares. 1906. Os estranguladores do Rio ou o crime da Rua da Carioca. Rio de Janeiro: Miotto.

PORTO, Ana Gomes. 2009. "Novelas sangrentas: literatura de crime no Brasil (1870-1920)". Campinas: Unicamp, tese de doutorado em História. Online: <libdigi.unicamp.br/document/?code=000436292>. Acesso em 3 de outubro de 2009.

SALEM, James M. n.d. "African American Songwriters and Performers in the Coon Song Era: Black Innovation and American Popular Music". Columbia Journal of American Studies. Online: $<$ www.columbia.edu/cu/cjas/salem 1.html>. Acesso em 25 de julho de 2008. 
SANDRONI, Carlos. 2001. Feitiço decente: transformações do samba no Rio de Janeiro (1917-1933). Rio de Janeiro: Zahar. SANTOS, Alcino; Gracio BARBALHO, Jairo SEVERIANO, Miguel Ângelo AZEVEDO (Nirez). 1982. Discografia brasileira 78 RPM: 1902-1964. Rio de Janeiro: Funarte, v. 1.

SEUBERT, David. 2008. "Cylinder Recordings: a Primer". Cylinder Preservation and Digitization Project. Universidade da Califórnia, Santa Bárbara. Online: <cylinders.library.ucsb.edu/history.php>. Acesso em 15 de junho de 2008.

SEVERIANO, Jairo. 2008. Uma história da música popular brasileira: das origens à modernidade. São Paulo: Editora 34. SILVA, Adalberto Prado e; M. B. LOURENÇO Filho, Francisco MARINS, Theodoro Henrique MAURER Jr, José CURADO, Ary Tupynambá PEIREIRA e Aleixo ROSUT (orgs). 1975. Dicionário brasileiro da língua portuguesa. São Paulo: Mirador. SILVA, Marilia T. Barbosa da e Arthur L. de OLIVEIRA Filho. 1979. Filho de Ogum bexiguento. Rio de Janeiro: Funarte. TINHORÃO, José Ramos. 1976. Música popular: os sons que vêm da rua. Rio de Janeiro: Edições Tinhorão. VASCONCELOS, Ary. 1985. A nova música da República Velha. Rio de Janeiro: edição independente.

---. 1977. Panorama da música popular brasileira na belle époque. Rio de Janeiro: Sant'Anna.

---. 1964. Panorama da música popular brasileira. São Paulo: Martins, v. 1.

VEDANA, Hardy. 2006. A Elétrica e os Discos Gaúcho. Porto Alegre: edição do autor.

WONDRICH, David. 2003. Stomp and Swerve: American Music Gets Hot, 1843-1924. Chicago: A Capella.

XAVIER, Valêncio. 2004. "Os estranguladores da Fé em Deus: os crimes de Rocca e Carletto". Crimes à moda antiga. São Paulo: Publifolha, p.6-25.

\section{Referências fonográficas}

Música e letra de AUTOR DESCONHECIDO, com Edmundo André (voz) e piano. A Risada. Disco Odeon, 40.631. Aprox. 1904-1907: Brasil. com Eduardo das Neves (voz) e violão. As Eleições de Piancó. Disco Odeon, 108.760. Aprox. 1907-1912: Brasil.

George W. JOHNSON (música, letra e voz) com acompanhamento de piano. "Laughing Song". Provavelmente, cilindro de cera da New Jersey, sem número. Aprox. 1894-1898. Lost Sounds: Blacks and the Birth of the Recording Industry, 1891-1922. Archeophone, caixa com 2 CDs, ARCH 105. 2005: EUA.

(música), letra de autor desconhecido, com Mário Pinheiro (voz) e piano. A Vacina obrigatória. Disco Odeon, 40.169. Aprox. 1904-1907: Brasil.

(música), letra de autor desconhecido, com Geraldo Magalhães (voz) e piano. Febre amarela. Disco Odeon, 40.493. Aprox. 1904-1907: Brasil.

(música) e Vagalume (letra), com Eduardo das Neves (voz) e violão. Gargalhada. Disco Odeon, 108.077. Aprox. 1906: Brasil.

Kerry MILLS (música), com a Sousa's Band. "At a Georgia Camp Meeting". Disco Victor, 315. Aprox. 1902: EUA. Stomp and Swerve: American Music Gets Hot. CD Archeophone, ARCH 1003. 2003: EUA. (música), com a Banda da Casa Edison. Cake walk. Disco Odeon, 40.057. Aprox. 1904-1907: Brasil. (música), com a Banda do Corpo de Bombeiros. At a Georgia Camp Meeting. Disco Odeon, 40.115. Aprox. 19041907: Brasil. (música), com Artur Camilo (piano). Cake walk. Disco Odeon, 40.210. Aprox. 1904-1907: Brasil. (música), com a Banda da Casa Edison. Cake walk. Disco Odeon, 10.015. Aprox. 1907-1913: Brasil. (música), letra de autor desconhecido, com J.G. Leonardo (voz) a banda. O Mulato de arrelia. Disco Victor, 98.720. Aprox. 1908-1912: Brasil. 


\section{Notas}

1 Sobre a composição da massa do disco, vide FRANCESCHI (1984, p.107-108; 2002, p.212).

2 Nem sempre é fácil identificar as unidades de riso nas gargalhadas ritmadas e moduladas em timbre e altura desta cançoneta. A presente transcrição resulta de comparações entre a percepção auditiva e representações visuais do envelope sonoro.

3 Nas citações que se seguem, mantenho as ortografias originais.

4 Fonogramas Odeon 108.086 e 108.341, Favorite Record 1-452.004, Victor Record 98.486 e Columbia B-101.

5 Ou a transferências distintas de uma mesma chapa: o site do IMS não fornece esclarecimentos.

6 De acordo com FRANCESCHI (2002, p.207), nas gravações cantadas da Casa Edison o anúncio era feito pelo próprio intérprete. 0 sotaque português do anunciante aparentemente o contradiz, no caso do fonograma 108.077.

7 No primeiro dos cinco CD-ROMs que acompanham o livro A Casa Edison e seu tempo, Humberto Franceschi divulgou cópias dos seguintes catálogos e suplementos:

- 1900, capa do catálogo 1900: phonographos, graphophonos, phonogrammas, pertences para importação direta por Fred Figner, Rio de Janeiro;

- 1902, Catalogo de 1902 (capa, duas páginas não numeradas, p.3-16 e 25-54, capa traseira), Casa Edison, Rio de Janeiro;

- $\quad$ 1913, Supplemento de abril e maio 1913 (capa, duas páginas não numeradas, p.4-7, capa traseira), Casa Edison, Rio de Janeiro; Supplemento de agosto, setembro e outubro de 1913 (capa, p.2-7, capa traseira), Casa Edison, Rio de Janeiro; Supplemento A (capa, uma página não numerada, p.4-15, duas páginas não numeradas), Casa Edison, Rio de Janeiro; Supplemento do mez de dezembro de 1913: discos gravados em Porto Alegre (capa, duas páginas não numeradas, p.4-11, capa traseira), Casa Edison, Rio de Janeiro;

- 1914, Supplemento de janeiro a maio de 1914 (capa, página não numerada, p.3-11, duas páginas não numeradas), Casa Odeon, São Paulo (a primeira e a última páginas e os cabeçalhos do miolo, excetuadas as duas páginas finais, indicam "Casa Edison"); Supplemento de outubro, novembro e dezembro (capa, p.5-15, capa traseira), Casa Odeon, São Paulo;

- 1915, Discos Odeon 1915 Casa Murano (capa, página sem número, p.8-70), Casa Murano, São Paulo;

- $\quad$ 1918, Catalogo geral (capa, seis páginas sem número, p.6-224), Casa Edison, Rio de Janeiro;

- 1919, Catalogo geral 1919 (capa, seis páginas sem número, p.8-123, 125-142, 144-208, duas páginas sem número), Casa Edison, Rio de Janeiro;

- 1920, 1920: catalogo geral (capa, quatro páginas sem número, p.6-78, três páginas sem número, p.139-208, duas páginas sem número), Casa Edison, Rio de Janeiro;

- 1924, Catalogo geral de discos duplos Odeon (capa, três páginas sem número, p.4-85, duas páginas sem número), Casa Edison, Rio de Janeiro;

- 1926, Catalogo geral de discos duplos Odeon (capa, três páginas sem número, p.4-47, duas páginas sem número), Casa Edison, Rio de Janeiro.

8 É por sinédoque (e por praticidade) que, nos catálogos da Casa Edison, o número de um dos fonogramas designa a chapa.

9 Na cópia do primeiro volume da Discografia que pertenceu ao colecionador paranaense Paulo José da Costa (SANTOS et al. 1982, p.85), uma anotação a lápis indica a existência de uma chapa combinando os fonogramas 108.085 (Balancê, com Eduardo das Neves) e 108.289 (Moro ả beira do mar, com Geraldo Magalhães).

10 De acordo com FRANCESCHI (2008), estas fichas não correspondem a seu próprio banco de dados.

11 Os dois primeiros realizaram transferências digitais de chapas de goma-laca para o selo Naxos Historical, o terceiro é responsável pelas transferências digitais do Centre for the History and Analysis of Recorded Music (CHARM). Sobre a abordagem do CHARM, vide HALLIFAX (2002).

120 "Livro de Registros de Gravações da Casa Edison", reproduzido por FRANCESCHI (2002) identifica o fonograma 10.413, desconhecido de SANTOS et al. (1982, p.80-81).

13 Baseados em catálogos da época, SANTOS et al. (1982, p.121) afirmam que os discos de 35 centímetros permitiam gravações de até seis minutos de duração. Esta informação é confirmada: em 1920: catalogo geral (p.73); no Catalogo geral de discos duplos Odeon de 1924 (p.84); no Catalogo geral de discos duplos Odeon de 1926 (p.47). Em todos eles, a segunda faixa da chapa 70.083, Ballada do Guarany, na voz da soprano M. Pereira, é anunciada como durando seis minutos. 0 fato desta chapa não aparecer nos catálogos de 1915, 1918 e 1919 , todos eles contendo gravações da série 70.000-70.084, pode levantar suspeitas quanto à data de 1912, fornecida por SANTOS et al. (1982, p.121) como limite final da série.

140 termo "série" corresponde ali ao que SANTOS et al. (1982) designam por "matriz", e não ao que estes, FRANCESCHI (1984 e 2002) e o presente autor entendem pelo termo.

15 No "Livro de Registros", "№s" corresponde ao que SANTOS et al. (1982) designam por "número do disco" e o IMS por "número do álbum", mas que prefiro chamar de "número de fonograma".

16 Sobre gravação e prensagem em Porto Alegre, vide VEDANA (2006) e FRANCESCHI (1984, p.89-92; 2002, p.177-191).

17 Não é impossivel que a hipótese de Santos não se confirme e que as tomadas para a série 108.000 tenham-se registrado em outro livro. Por outro lado, SANTOS et al. (1982, p.106-114) dão dezembro de 1912 como "data do lançamento" de trinta e três dos fonogramas da série 108.000. A possibilidade do decurso de um período considerável de tempo entre a data de gravação e lançamento deve ser levada em conta.

18 Todos os títulos abaixo estão disponiveis, por streaming, no site do IMS.

19 De acordo com a ficha do fonograma do acervo Tinhorão (o único no qual esta gravação está disponivel online), um "lundu alegre".

20 Para VASCONCELOS (1977, p.284), um "lundu alegre".

21 Anunciado no fonograma como "uma noite agitada numa república de estudantes".

22 Para VASCONCELOS (1977, p.332), Rolo em um bonde é uma "confusão cômica", um "sketch certamente improvisado, durante o qual Mário Pinheiro canta uma modinha de um autor desconhecido".

23 A referência ao acompanhamento de coro não é fornecida por SANTOS et al. (1982, p.115), mas aparece nos catálogos de 1915, 1918, 1919, 1920, 1924 e 1926. Segundo VASCONCELOS (1977, p.284), o coro é constituído por Mário Pinheiro e Nozinho (Carlos Vasques). 0 fonograma anuncia: "cantado e acompanhado ao violão por Eduardo das Neves e coro feito por Mário e Sinhozinho".

24 A letra de 0 Aquidabã aparece em VASCONCELOS (1985, p.42-43) e LISBOA (1996, p.183).

25 Sobre "o crime do ano", vide PINHEIRO (1906), BARBOSA (1923, p.97-102), ALENCAR (1976, p.100), XAVIER (2004), FERLIM (2006, p.76-77) e PORTO (2009, p.176-202).

26 TINHORÃO (1976, p.40-41) vai mais longe, atribuindo a Eduardo das Neves o papel de fundador da tradição, viva na primeira década do século XX, de cantar sempre o drama ocorrido na cidade, um caso escandaloso ou um acontecimento político.

27 É verdade que o crime da Rua da Carioca ainda era assunto em dezembro de 1907, quando Carletto e Rocca foram levados a julgamento. "Justiça, senhores da terra, justiça mais uma vez, trinta anos não é demais para quem tal crime fez", canta Eduardo das Neves, seja solicitando a pena máxima, antes do julgamento, seja endossando-a, depois. 
28 Sobre a produção e a comercialização de cilindros no Brasil, vide FRANCESCHI (1984, p.11-52; 2002, p.15-59).

29 Fred Figner recebeu a prova da primeira chapa inteiramente produzida no Brasil em 21 de dezembro de 1912, embora não se saiba ao certo que fonogramas ela contivesse (FRANCESCHI 2002, p.203).

30 Em Registro sonoro por meios mecânicos no Brasil, Franceschi afirma que o selo Bandeira Brasileira aplicou-se a discos "prensados entre 1908 e 1912" (FRANCESCHI 1984, p.75).

31 SANTOS et al. (1982, p.52) apresentam Febre Amarela como uma "gargalhada".

320 primeiro volume da Discografia brasileira 78 RPM registra, sob o selo Zon-0-Phone, o primeiro da Casa Edison: Cometa Biela, uma "gargalhada", com o ator Veloso, número de série 1.674 (SANTOS et al. 1982, p.17); América e Espanha, "gargalhadas", com o ator Veloso, número de série X-816 (SANTOS et al. 1982, p.30); Cometa Biela, "gargalhadas", com o ator Veloso, número de série X-821 (SANTOS et al. 1982, p.30). De acordo com SANTOS et al. (1982, p.31), as séries 1.500 e X-500 consistem de discos de sete e dez polegadas, respectivamente. Apesar da numeração inferior, elas seriam posteriores às séries Zon-0-Phone 10.000 e X-1.000, nas quais realizaram-se as primeiras gravações da Casa Edison. De acordo com SANTOS et al. (1982, p.32), "as séries Zon-0-Phone devem ir até meados de 1904, quando Figner passa a usar a Odeon".

33 De acordo com FRANCESCHI (2008), os cilindros brasileiros eram constituídos de um núcleo de cera recoberto por uma camada externa raspável, também de cera. Com o calor, a dilatação do núcleo produzia fissuras na camada externa, menos facilmente dilatável, que terminava por fender-se.

340 texto da "nova gargalhada" de Eduardo das Neves mostra, já em 1905, o costume latino-americano de chamar os brasileiros de "macaquitos" (vide NEVES 1905, p.34).

35 Citado por João do Rio em 1908, com variações, na coletânea A alma encantada das ruas (BARRETO 1910, p.305-306).

36 Sobre Johnson, vide ABBOT e SEROFF (2002, p.93 e 103-4), BROOKS (2004, p.13-71) e SALEM (n.d.). Toda esta seção baseia-se na primeira parte do livro de Brooks.

37 As gravações originais, em cilindros revestidos de folha de estanho, sendo muito pereciveis, esta questão dificilmente será esclarecida.

$38 \mathrm{Um}$ minstrel show era "um espetáculo teatral de longa duração estrelando intérpretes com os rostos pintados de preto que executavam canções, danças e números cômicos baseados em paródias e estereótipos da vida e dos costumes dos americanos africanos" (BURNIM e MAULTSBY 2006, p.646).

390 texto reproduzido baseia-se no da partitura de 1894, com alterações em função da gravação listada nas referências e do texto fornecido por BROOKS (2004, p.31). Como não se utilizava ainda o sistema de matrizes, cada execução gerava três ou quatro cilindros vendáveis. As performances gravadas podiam, portanto, diferir consideravelmente. Por outro lado, a partitura está muito longe da variedade ritmica da criação de Johnson.

40 É curioso observar que a pecha de janota foi lançada contra Eduardo das Neves pelo escritor (dândi mulato, homossexual, cocainômano e imortal) João do Rio em 1908: "o Eduardo das Neves tinha sido bombeiro, antes de ser notavel. Quando foi numero de music-hall, perdeu a tramontana e passou a andar de smoking azul e chapéo de seda" (BARRETO 1910, p.305).

41 Há aqui um trocadilho intraduzivel entre apple of their eye, literalmente "a maçã de seus olhos", significando "a menina de seus olhos", e quince, literalmente, "marmelo", mas também, "uma pessoa fraca, efeminada; uma pessoa indecisamente tola" (PARTRIDGE 1989, p.360).

42 In the sweet by and by, traduzido aqui por "se deus quiser", é uma referência ao hino de Sanford Fillmore Bennett e Joseph P. Webster In the Sweet Bye and Bye, publicado em 1868.

43 "Estilo de canção popular do final do século XIX e início do XX que apresentava uma visão estereotipada dos americanos africanos, frequentemente interpretada por cantores brancos com as caras pintadas de preto" (BURNIM e MAULTSBY 2006, p.644).

44 "Dança que parodia o comportamento da classe superior branca, originalmente executada por escravos americanos africanos; a melhor performance recebia um prêmio, normalmente um bolo, ao qual a dança deve seu nome" (BURNIM e MAULTSBY 2006, p.644).

45 Traduzido ao alemão e publicado no Illustrierte Zeitung Leipzig em 1903, At a Georgia Camp Meeting tornou-se "uma das peças mais populares na Alemanha e na Áustria, presumivelmente contribuindo para a divulgação (da música) do cakewalk nos paises de língua alemã" (HARER 2006, p.137 e 140).

46 Sou grato à pesquisadora austriaca Ingeborg Harer por ter identificado, no fonograma Victor, o cakewalk de Mills, tendo me transmitido esta informação em mensagem eletrônica de 16 de abril de 2008.

47 No inicio dos anos 1900, Sylvester Russell tornou-se o primeiro crítico profissional de música de ascendência americana africana (ABBOT e SEROFF 2002, p.190).

48 Fundado em 1888 por Edward Elder, que fugira da escravidão no sul para instalar-se em Indianápolis em 1882, o semanário Indianapolis Freeman tornou-se rapidamente uma das publicações negras de maior circulação, sendo adotado por profissionais do espetáculo e músicos negros como fonte principal de noticias e fofocas (ABBOT e SEROFF 2002, p.xii).

49 Sobre o lundu, vide o capitulo "Doces lundus, pra nhonhô sonhar..." no livro de Carlos SANDRONI (2001, p.39-61).

50 Sobre esta problemática, vide BÉHAGUE 2002.

Carlos Palombini doutorou-se em Música pela Universidade de Durham, no Reino Unido, com a tese "Pierre Schaeffer's Typo-Morphology of Sonic Objects" (1993). Desenvolveu atividades de pesquisa e ensino na PUC-SP, Unicamp e UFPE antes de tornar-se professor de Musicologia na UFMG. Seus artigos e resenhas aparecem nos periódicos Computer Music Journal (MIT Press), Music and Letters (Oxford University Press), Leonardo (MIT Press), Organised Sound (Cambridge University Press), Echo (UCLA) etc. É pesquisador do CNPq e da FAPEMIG. Com a colaboração de Sophie Brunet, reconstituiu o Essai sur la radio et le cinéma: esthétique et technique des arts-relais, um original inédito de Pierre Schaeffer recentemente publicado na França (Paris: Allia, 2010). 